\title{
Atlantoaxial subluxation in the
}

\section{pediatric patient: Case series and literature review}

\section{Catherine A Mazzola ${ }^{1 *}$, Catherine Christie ${ }^{1}$, Isabel A Snee ${ }^{2}$ and Hamail lqbal ${ }^{3}$}

${ }^{1}$ New Jersey Pediatric Neuroscience Institute, Morristown, NJ, USA

${ }^{2}$ The University of Notre Dame, South Bend, IN, USA

${ }^{3}$ Rutgers University, New Brunswick, NJ, USA

\section{Abstract}

Objective: Atlantoaxial subluxation (AAS) occurs when there is misalignment of the atlantoaxial joint. Several etiologies confer increased risk of AAS in children, including neck trauma, inflammation, infection, or inherent ligamentous laxity of the cervical spine.

Methods: A single-center, retrospective case review was performed. Thirty-four patients with an ICD-10 diagnosis of S13.1 were identified. Demographics and clinical data were reviewed for etiology, imaging techniques, treatment, and clinical outcome.

Results: Out of thirty-four patients, twenty-two suffered cervical spine trauma, seven presented with Grisel's Syndrome, four presented with ligamentous laxity, and one had an unrecognizable etiology. Most diagnoses of cervical spine subluxation and/or instability were detected on computerized tomography (CT), while radiography and magnetic resonance imaging (MRI) were largely performed for follow-up monitoring. Six patients underwent cervical spine fusion, five had halo traction, twelve wore a hard and/or soft collar without having surgery or halo traction, and eight were referred to physical therapy without other interventions.

Conclusion: Pediatric patients with atlantoaxial subluxation may benefit from limited 3D CT scans of the upper cervical spine for accurate diagnosis. Conservative treatment with hard cervical collar and immobilization after reduction may be attempted, but halo traction and halo vest immobilization may be necessary. If non-operative treatment fails, cervical spine internal reduction and fixation may be necessary to maintain normal C1-C2 alignment.
More Information

*Address for Correspondence: Catherine Mazzola, MD, New Jersey Pediatric Neuroscience Institute, USA, Tel: (973) 326-9000; Email: cmazzola@njpni.com

Submitted: 09 November 2020 Approved: 25 November 2020 Published: 26 November 2020

How to cite this article: Mazzola CA, Christie C Snee IA, Iqbal H. Atlantoaxial subluxation in the pediatric patient: Case series and literature review. J Neurosci Neurol Disord. 2020; 4: 069-074

DOI: 10.29328/journal.jnnd.1001037

ORCiD: orcid.org/0000-0002-9146-1800

Copyright: @ 2020 Mazzola CA, et al. This is an open access article distributed under the Creative Commons Attribution License, which permits unrestricted use, distribution, and reproduction in any medium, provided the original work is properly cited.

Keywords: Atlantoaxial subluxation; C1-C2 subluxation; Cervical spine subluxation; Cervical spine trauma; Grisel's syndrome

Abbreviations: AAS: Atlantoaxial Subluxation CT: Computerized Tomography; ER: Emergency Room; GS: Grisel's Syndrome; MRI: Magnetic Resonance Imaging; URTI: Upper Respiratory Tract Infection; 3D: Three Dimensional

Check for updates

OPEN ACCESS

\section{Introduction}

Atlantoaxial subluxation (AAS) refers to misalignment of the C1-C2 vertebrae that may impair cervical rotation or movement. Cervical spine trauma, even when mild or unrecognized, may instigate AAS. On the other hand, Grisel's syndrome (GS), both rare and nontraumatic, causes AAS typically from surrounding soft tissue inflammation [1]. The overwhelming majority of those who suffer AAS are pediatric, with $90 \%$ of patients under twenty-one [2] and of those, approximately $68 \%$ under twelve [3]. Children are more vulnerable due to their larger head size, more flexible joints and ligaments, a shallower and more horizontally positioned facet joint, more retropharyngeal lymph nodes, and generally richer lymphatic system [4]. Patients tend to have a history of head or neck infection or recent maxillofacial or otorhinolaryngology procedures [1]. Moreover, they may also have conditions associated with ligamentous laxity, such as Down syndrome, Marfan's syndrome, Klippel-Feil syndrome, osteogenesis imperfecta, neurofibromatosis, or any conditions that increase ligamentous injury, degenerative changes, or affect spinal stability $[1,5,6]$.

The majority of patients present with persistent torticollis, sometimes painful, along with neck stiffness [4,7]. They also have an abnormal head posture, or "Cock Robin" tilt, in which the chin is rotated to one direction while the neck has been tilted or flexed to the opposite side [4]. Early GS may only show rotational deformity of the atlantoaxial joint as described by the Fielding and Hawkins's graded classification, each type requiring specific treatment (Figure 1) [8]. 
A
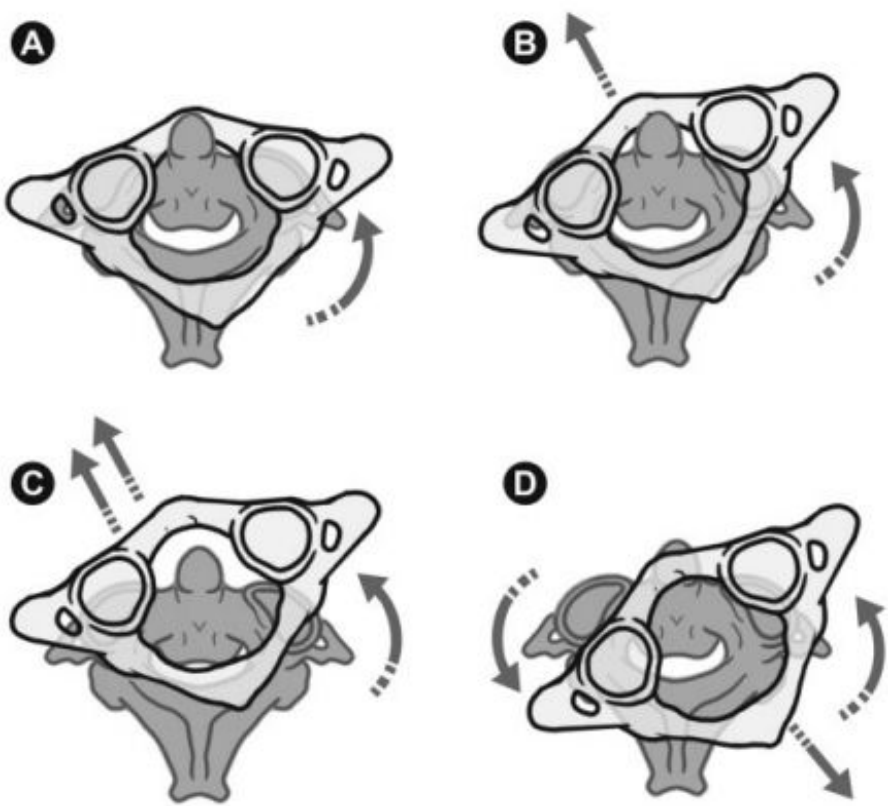

Figure 1: Drawing of Fielding and Hawkins classification of the atlantoaxial joint deformity. Type I (A) no subluxation but rotation of atlas (less than $3 \mathrm{~mm}$ of atlas anterior displacement). Type II (B) unilateral subluxation of one joint with atlas anterior displacement of $3-5 \mathrm{~mm}$; possible deficient transverse ligament. Type III (C) ventral subluxation of atlas in both joints, atlas anterior displacement greater than $5 \mathrm{~mm}$, deficient transverse and alar ligaments. Type IV (D) dorsal subluxation of atlas, posterior atlas displacement and deficient odontoid process; possible fractured Dens axis or congenital Dens-aplasia. (Reprinted with permission from Barcelos ACES, Patriota GC, Netto AU. Nontraumatic atlantoaxial rotatory subluxation grisel syndrome. Case report and literature review. Global Spine J. 2014; 4: 179-186).

\section{Methods}

\section{Overview}

A single center, retrospective review of patients was performed to evaluate and improve our ability to identify, diagnose, and treat children with AAS. Data from 2005 to July 2020 were reviewed.

\section{Study population}

Patients were identified for potential inclusion in the data analysis through a Level III, single-center, retrospective case series. Using the electronic medical record (EMR) General Electric (GE) Centricity database, a chart review/ report was done for patients with any diagnosis of ICD-10 S13.1, which refers to the "...subluxation and dislocation of cervical vertebrae" (2020 ICD-10-CM Diagnosis Code S13.1: Subluxation and dislocation of cervical vertebrae). Additionally, a review of patients with cervical spine instability was done (ICD-10 M53.2) to be certain no patients were missed. This became the preliminary inclusion criteria for the patient review. After combing through this patient pool, only patients whose chart history confirmed AAS by physician clinical diagnosis were included. From there, a total of thirtyfour patients were selected from the database to be analyzed for this study.

\section{Results}

In our cohort of thirty-four patients, twenty-two (64.7\%) suffered cervical spine trauma, seven $(20.6 \%)$ presented with GS, two of which underwent prior tonsillectomy, four $(11.8 \%)$ presented with ligamentous laxity likely secondary to Down syndrome, and one patient $(2.9 \%)$ had an unrecognizable cause.

Data on imaging modalities were collected and analyzed. Accounting for the total number of times radiological tests performed across the cohort, cervical spine subluxation and/ or instability was detected on nine out of eighteen radiographs, nineteen out of twenty-five computerized tomography (CT) scans, and twelve out of fourteen magnetic resonance imaging studies (MRI).

Concerning treatment, six patients (17.6\%) underwent cervical spine fusion surgery, five $(14.7 \%)$ had a halo placed, twelve (35.3\%) wore a hard and/or soft cervical collar without having surgery or a halo, and eight (23.5\%) were referred to physical therapy without any other intervention. The mean follow-up length in weeks was 39.8 for surgery, 59.4 for halo treatment, 44.3 for cervical collar use without surgery or a halo, and 60 weeks for physical therapy without any other intervention. It is important to note, however, that the mean follow up length may not be very indicative of the efficiency of different treatment options as external factors can greatly influence follow up times. For instance, three of the eight patients referred to physical therapy had no follow up after the initial visit.

\section{Case reports}

\section{Patient 1}

A ten-year-old male patient with "Cock-Robin" torticollis and Down Syndrome presented to the clinic and was sent to the emergency room (ER). Although the initial x-ray report of the cervical spine only reported slight torticollis, the child could not turn his head. MRI of the cervical spine without contrast revealed subluxation without spinal injury. He was subsequently started on muscle relaxant (oral Baclofen), manually reduced, and placed in a hard collar. The atlantoaxial subluxation recurred, and another manual reduction and orthosis application performed.

However, after AAS recurred three times, the child was placed in halo traction, and then a halo vest. Halo immobilization was maintained for four months. A CT study of the cervical spine without contrast and a 3D reconstruction scan done a week after halo placement demonstrated improved alignment. A follow-up CT study 3D reconstruction done three months later showed no subluxation. After removal of halo immobilization, the patient wore a hard collar for two months, then a soft collar for two months along with 
physical therapy. Follow up cervical spine radiograph studies with lateral, frontal, and open-mouth views done on both three months and seven months after the collar was removed confirmed subluxation resolution.

\section{Patient 2}

A seven-year-old girl presented with neck pain and torticollis after falling from her bed. Her pediatrician referred her to a pediatric orthopedic surgeon after several days of a "Cock-Robin" head position. The child was neurologically intact except for persistent torticollis and pain. Cervical spine x-rays were reported as "normal", except for a fractured clavicle (Figure 2). The patient was referred to pediatric neurosurgery after several weeks. The child was seen and referred to the emergency room (ER) where a computed tomography (CT) and 3D reconstruction of the cervical spine were ordered. CT revealed C1-C2 subluxation. An MRI of the cervical spinal canal done was unremarkable. The patient was started on muscle relaxants and manually reduced. When the child was in a neutral position, a hard collar was applied.

Despite application of the cervical orthosis, the following day, the "Cock Robin" head position recurred. After three attempts and recurrent subluxation, the patient underwent halo traction. Once cervical spine x-rays demonstrated C1$\mathrm{C} 2$ alignment, a halo vest placement was performed. Followup CT demonstrated improved alignment. After halo vest immobilization was maintained for three months, a hard collar was worn for two months followed by a soft collar. Neck strengthening with physical therapy was recommended. Follow-up radiographs performed five and nine months after the trauma confirmed proper cervical spine alignment.

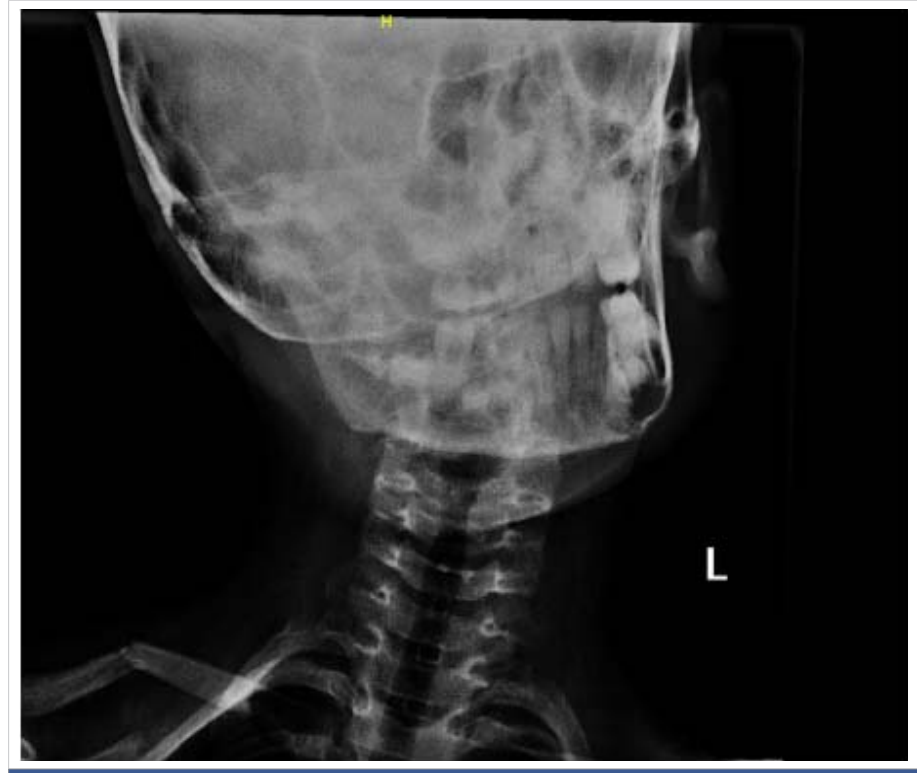

Figure 2: Image of cervical x-ray of patient upon presentation to ER. While read as unremarkable except for a fractured clavicle during the time, it is quite clear that AAS is present, as indicated by the quite prominent "Cock Robin" head position displayed above.

\section{Discussion}

\section{Etiology}

While cervical spine trauma may cause AAS, in some cases there does not appear to be any apparent trauma. Mild trauma with certain underlying etiologies may predispose children to atlantoaxial subluxation. Described as the "twohit hypothesis", Battiata and Pazos define the first "hit" as a pre-existing cervical ligament laxity in pediatrics at baseline ( $4.5 \mathrm{~mm}$ ) compared to normal adults (2.5 to $3 \mathrm{~mm}$ ) [9]. Such predisposition may arise from genetic disorders, particularly Down Syndrome in which there is a manifestation of flat, wide occipital condyles and flat C1 articular surfaces [10]. The second hit is a cervical muscle spasm most likely caused by inflammation or infection which may occur in the parapharyngo-vertebral area [7]. Inflammatory processes in the neck's soft issues, such as postoperative inflammation after an adenoidectomy, peritonsillar, or retropharyngeal abscess, may lead to ligamentous laxity [11]. Since the pharyngovertebral veins drain the nasopharynx and connect to the periodontoid venous plexuses, any pharyngeal inflammatory process may cause contiguous spread to the atlantoaxial ligaments $[12,13]$. Spreading infection or inflammation in the surrounding tissues and prevertebral facia induces ligament laxity, and may affect nearby muscles and thus causing the AAS [14].

Another theory suggests cervical lymphadenitis after a nasopharyngeal infection may instigate torticollis through suboccipital and paravertebral muscle spasms $[4,8]$. Thus, previous inflammation in the $\mathrm{C} 1-\mathrm{C} 2$ prevertebral soft tissue increases risk of subluxation [7].In a study of sixteen pediatric GS patients, $81.25 \%$ developed GS from an upper respiratory tract infection (URTI) and $18.75 \%$ from surgical interventions [13]. Such URTIs include pharyngitis, adenotonsillitis, tonsillar abscesses, cervical abscesses and otitis media $[5,13]$.

Bolstering this claim, a literature review of 103 GS patients found that $48 \%$ of the cases were caused by infection, followed by postoperative cases (40\%) [6]. Of the infection cases, URTIs caused $83 \%$ of the cases, retropharyngeal abscess $11 \%$, otitis media $4 \%$, and mumps $2 \%$ [6]. Of the postoperative cases, $78 \%$ adenotonsillectomy, $15 \%$ post-pharyngoplasty, $2.5 \%$ post-otoplasty, $2.5 \%$ post-tympanomastoidectomy, and $2.5 \%$ post-grommets [6]. Other surgical interventions may also lead to GS, such as tonsillectomy, adenoidectomy, and mastoidectomy [13].

\section{Imaging techniques}

Like other neurosurgical conditions, AAS is diagnosed using both clinical and radiological evaluation. While computerized tomography (CT) is regarded as the optimal imaging technique for the cervical spine, its high levels of radiation exposure present a concern, especially for children, due the proximity of the thyroid to the atlantoaxial region. Modalities with lower 
or no radiation doses, such as radiography and magnetic resonance imaging (MRI), have also been used to image and diagnose potential AAS. Thus, it is important to understand the risks and benefits associated with different imaging techniques to accurately detect instability and subluxation while limiting radiation exposure in children.

Cervical spine $x$-rays often serve as the first form of imaging for potential neck injuries due to its availability and relatively low radiation dosage [16]. Compared to a cervical spine CT scan, which produce an average effective radiation dosage of six millisieverts ( $\mathrm{mSv}$ ), a five-view cervical spine $\mathrm{x}$-ray series produces an average effective dosage of $0.2 \mathrm{mSv}[17,18]$. A variety of angles are required for adequate visualization of the bony contours of the cervical spine, including lateral, anteroposterior, and open-mouth views [19]. Radiographs can also suggest bone injuries through indirect signs such as soft tissue swelling. Radiography has a sensitivity of around $90 \%$ for detection of bony cervical spine injuries, making it an adequate screening method for patients who show no neurological abnormalities upon examination [16]. For infants and young children, cervical spine x-rays may be difficult to interpret due to obstruction of the view of $\mathrm{C} 1$ and $\mathrm{C} 2$ by the mandible. Infants and children may be uncooperative during imaging studies.

The common imaging modality of choice for imaging the cervical spine is CT scan due to its sensitivity of around $98 \%$ $100 \%$ for detecting cervical spine injury $[16,20]$. By defining the location and, through three dimensional (3D) reconstruction, the orientation of displaced vertebrae in relation to the spinal canal, CT scans provide a high resolution image of potential cervical spine abnormalities. Flexion-extension studies can also address ligamentous injuries potentially indicative of atlantoaxial instability and subluxation, although most infants in children with AAS cannot perform flexion and extension of the cervical spine $[19,21]$.

MRI of the cervical spine can also be useful in detecting AAS. Although not the best imaging technique for the cervical vertebrae or bone, MRI generates high quality images of soft tissue, making it an appropriate tool for detecting inflammation or laxity of cervical ligaments or injury of the spinal cord. ${ }^{16}$ In a report of an eight year old female presenting with torticollis and neck pain following Mycoplasma pneumoniae infection, MRI of the brain and cervical spine showing signs of inflammation in adjacent neck tissue allowed the authors to make a diagnosis of Grisel's Syndrome secondary to $M$. pneumoniae infection [22]. Moreover, though it is limited in availability, time, and cost, the major benefit of MRI is its use of magnetic fields and radio waves instead of ionizing radiation, suggesting its role as a valuable tool for long-term monitoring of the cervical spine [16].

In assessing the difference between radiography and CT, cervical subluxation or instability were present in $50 \%$ of the radiographs done before treatment while they were present in $76 \%$ of the CT scans done before treatment in our cohort of cases. Furthermore, in a case of a two year old female, a CT scan confirming a fracture of the anterior arch of the atlas was performed after persistent neck pain despite an unremarkable initial radiograph study [19]. Hale, et al. compared the quality of radiograph and CT scan for detecting cervical spine injuries from various cases, concluding a $98 \%$ sensitivity for CT and only $52 \%$ for radiography, where there were no injuries detected on a radiograph that were not also detected on a CT scan [20]. In consideration of the ossification process spanning much of childhood, with cervical spine ossification not completing until five to nine years of age, this distinction is likely due to the greater resolution of CT [19]. Thus, it is recommended for patients presenting with continuous neck pain and for those at a particularly high-risk of cervical subluxation and/or instability to have CT scans performed instead of plain radiographs as missing cervical spine injuries could have severe consequences. ${ }^{16}$ Nonetheless, radiography serves as a useful tool for ensuring optimal positioning of the spine and halo and monitoring the progression of treatment due to the lower radiation dosage [23].

Collectively, it is suggested that CT scans provide greater quality imaging for detecting cervical spine instability and subluxation than radiography and MRI; however, it should be used conservatively, particularly in cases with severe symptoms and high suspicion for subluxation $[9,16,19]$. Since recurrent subluxation has been described, follow up imaging may be recommended. In many cases, cervical spine x-rays or MRI may be sufficient [13].

\section{Additional studies}

Additional studies such as blood culture, erythrocyte sedimentation rate (ESR), $C$ reactive protein (CRP) and procalcitonin, may be useful to evaluate inflammation and infection in children with suspected GS [13]. Once infection or inflammation has resolved, and subluxation has been corrected, the risk of recurrence is minimal [6].

\section{Treatment options}

Treatment of AAS depends on both the etiology and severity. While mild to moderate AAS could be resolved with manual manipulation, severe cases require Halo traction or cervical spine fusion. ${ }^{22}$ Moreover, mild to moderate subluxation secondary to GS can be effectively resolved by treating the infectious process with antibiotics and steroids [22]. Fielding, et al. summarized an overall classification for AAS that can be used to determine the appropriate treatment plan for a patient (Table 1). In the patient sample presented in this report, the majority underwent non-invasive treatments: use of cervical collars or physical therapy. Only 11 patients required Halo placement or fusion surgery. While the mean follow-up duration was the lowest for cervical spine fusion surgery, follow up length may not be a significant factor in 


\begin{tabular}{|c|c|c|}
\hline Classification & Presentation & Treatment \\
\hline Type I & $\begin{array}{l}\text { Simple rotation without anterior displacement of the atlas and no damage } \\
\text { to the transverse ligament }\end{array}$ & $\begin{array}{c}\text { Antibiotics, muscle relaxants, immobilization with a soft collar, and physical } \\
\text { therapy }\end{array}$ \\
\hline Type II & $\begin{array}{l}\text { Less than or equal to } 5 \mathrm{~mm} \text { anterior displacement of the atlas and some } \\
\text { deficit of the transverse ligament }\end{array}$ & Reduction and cervical traction with a rigid collar \\
\hline Type III & $\begin{array}{c}\text { Greater than } 5 \mathrm{~mm} \text { anterior displacement of the atlas, both lateral } \\
\text { atlantoaxial joints are subluxed anteriorly, and the transverse ligament and } \\
\text { articular facets are damaged }\end{array}$ & $\begin{array}{l}\text { Type III and IV are highly unstable lesions. Cervical traction with a Halo vest, } \\
\text { and in the event of neurological symptoms, decompression and arthrodesis of } \\
\text { C1-C2 is required }\end{array}$ \\
\hline Type IV & $\begin{array}{l}\text { Rotation and posterior dislocation of the atlas; rare and more frequent in } \\
\text { adults with rheumatoid arthritis }\end{array}$ & \\
\hline
\end{tabular}

assessing the efficiency of different treatment options due to variability in patient adherence. Thus, treatment options should be discussed largely in terms of the presentation of AAS.

\section{Conclusion}

Atlantoaxial subluxation (AAS) refers to the imperfect alignment of the C1-C2 vertebrae that may result from cervical trauma or precipitate from infection and consequent inflammation to the cervical tissue, known as Grisel's syndrome. Regardless of the etiology, AAS must be diagnosed early to prevent further physical and possible neurological damage. We recommend that certain imaging modalities, specifically a CT scan, be performed from the outset to verify or reject the possibility of subluxation. 3D reconstruction views, in particular, are helpful. Occiput to C4 or C5 scans may limit or reduce radiation; however, CT scans must be used sparingly due to its relatively higher dosage of radiation in comparison with other imaging methods, especially within the pediatric population. Once AAS has been diagnosed, we recommend reduction following conservative treatment with a hard-cervical collar. However, when these methods prove unsuccessful, halo traction and the use of a halo vest immobilization may be necessary. If non-operative treatment fails, cervical spine internal reduction and fixation to correct AAS should be considered.

\section{Diclosures}

The authors report no conflict of interest concerning the materials or methods used in this study or the findings specified in this paper.

\section{References}

1. Khodabandeh M, Shakiba S, Alizadeh S, Eshaghi H. Grisel's syndrome associated with tonsillitis. ID Cases. 2018; 15: e00470.

PubMed: https://pubmed.ncbi.nlm.nih.gov/30656135/

2. Cornejo VJF, Martinez-Lage JF, Piqueras C, Gelabert A, Poza M. Inflammatory atlanto-axial subluxation (Grisel's syndrome) in children: clinical diagnosis and management. Childs Nerv Syst. 2003; 19: 342-347. PubMed: https://pubmed.ncbi.nlm.nih.gov/12783261/

3. Gourin CG, Kaper B, Abdu WA, Donegan JO. Nontraumatic atlantoaxial subluxation after retropharyngeal cellulitis: Grisel's syndrome. Am J Otolaryngol. 2002; 23: 60-65.

PubMed: https://pubmed.ncbi.nlm.nih.gov/11791252/

4. Das S, Chakraborty S, Das S. Grisel syndrome in otolaryngology: a case series with literature review. Indian J Otolaryngol Head Neck
Surg. 2019; 71(Suppl 1): 66-69

PubMed: https://pubmed.ncbi.nlm.nih.gov/31741933/

5. Bucak A, Ulu S, Aycicek A, Kacar E, Miman MC. Grisel's Syndrome: A Rare Complication following Adenotonsillectomy. Case Rep Otolaryngol. 2014; 2014: 703021.

6. Karkos PD, Benton J, Leong SC, Mushi E, Sivaji N, Assimakopoulos DA. Grisel's syndrome in otolaryngology: a systematic review. Int J Pediatr Otorhinolaryngol. 2007; 71: 1823-1827.

PubMed: https://pubmed.ncbi.nlm.nih.gov/17706297/

7. Park SH, Park SH, Lee SH. Grisel syndrome: pathophysiological evidence from magnetic resonance imaging findings. Ann Rehabil Med. 2013; 37: 713-716.

PubMed: https://pubmed.ncbi.nlm.nih.gov/24236260/

8. Barcelos ACES, Patriots GC, Netto AU. Nontraumatic atlantoaxial rotatory subluxation grisel syndrome. Case report and literature review. Global Spine J. 2014; 4:179-186.

PubMed: https://pubmed.ncbi.nlm.nih.gov/25083360/

9. Battiata AP, Pazos G. Grisel's syndrome: the two-hit hypothesis-a case report and literature review. Ear Nose Throat J. 2004; 83: 553-555. PubMed: https://pubmed.ncbi.nlm.nih.gov/15487635/

10. Brockmeyer DL. Common Pathological Conditions of the Pediatric Craniovertebral Junction and Cervical Spine. In: Brockmeyer DL, ed. Advanced Pediatric Craniocervical Surgery. New York: Thieme Medical Publishers. 2006; 43-54.

11. Pilge H, Prodinger PM, Bürklein D, Holzapfel NM, Lauen J. Nontraumatic subluxation of the atlanto-axial joint as rare form of acquired torticollis: diagnosis and clinical features of Grisel's syndrome. Spine. 2011; 36; E747-751.

PubMed: https://pubmed.ncbi.nlm.nih.gov/21178843/

12. Parke WW, Rothman RH, Brown MD. The pharyngovertebral veins: an anatomical rationale for Grisel's syndrome. J Bone Joint Surg Am. 1984; 66: 568-574.

PubMed: https://pubmed.ncbi.nlm.nih.gov/6707036/

13. Ozalp H, Hamzaoglu V, Avci E, Karatas D, Ismi O, et al. Early diagnosis of Grisel's syndrome in children with favorable outcome. Childs Nerv Syst. 2019; 35: 113-118.

PubMed: https://pubmed.ncbi.nlm.nih.gov/30361761/

14. Mathern GW, Batzdorf U. Grisel's syndrome. Cervical spine clinical, pathologic, and neurologic manifestations. Clin Orthop Relat Res. 1989; 244: 131-146.

PubMed: https://pubmed.ncbi.nlm.nih.gov/2663284/

15. Icd10data.com. 2020. 2020 ICD-10-CM Diagnosis Code S13.1: Subluxation And Dislocation Of Cervical Vertebrae. 2020. https://www. icd10data.com/ICD10CM/Codes/S00-T88/S10-S19/S13-/S13.1

16. Slaar A, Fockens MM, Wang J, Maas M, Wilson DJ, et al. Triage tools for detecting cervical spine injury in pediatric trauma patients. Cochrane Database Syst Rev. 2017; 12: CD011686. PubMed: https://pubmed.ncbi.nlm.nih.gov/29215711/

17. National Council on Radiation Protection and Measurements. Ionizing radiation exposure of the population of the United States. Bethesda, MD: NCRP; Report No. 160; 2009. 
18. Mettler FA, Huda W, Yoshizumi TT, Mahesh M. Effective Doses in Radiology and Diagnostic Nuclear Medicine: A Catalog. Radiology. 2008; 248: 254-263.

PubMed: https://pubmed.ncbi.nlm.nih.gov/18566177/

19. Hale AT, Alvarado A, Bey AK, Pruthi S, Mencio GA, et al. X-ray vs $\mathrm{CT}$ in identifying significant $\mathrm{C}$-spine injuries in the pediatric population. Childs Nerv Syst. 2017; 33: 1977-1983.

PubMed: https://pubmed.ncbi.nIm.nih.gov/28656384/

20. Sesia SB, Prüfer F, Walther M, Studer D. Delayed diagnosis of fractured anterior arch of the atlas in a young child. BMJ Case Rep. 2017; 2017: bcr2016214472.

PubMed: https://pubmed.ncbi.nlm.nih.gov/28073868/
21. Zhu X, Evans KN, El-Gharbawy A, Lee JY, Brooker JE, et al. Cervical Spine Injury From Unrecognized Craniocervical Instability in Severe Pierre Robin Sequence Associated With Skeletal Dysplasia. Cleft Palate Craniofac J. 2018; 55: 773-777.

PubMed: https://pubmed.ncbi.nlm.nih.gov/29489401/

22. Falsaperla R, Piattelli G, Marino S, Marino SD, Fontana A, et al. Grisel's syndrome caused by Mycoplasma pneumoniae infection: a case report and review of the literature. Childs Nerv Syst. 2019; 35: 523-527.

PubMed: https://pubmed.ncbi.nlm.nih.gov/30209598/

23. Verhofste BP, Glotzbecker MP, Birch CM, O'Neill NP, Hedequist GJ. Halo-gravity traction for the treatment of pediatric cervical spine disorders. J Neurosurg Pediatr. 2019; 1-10.

PubMed: https://pubmed.ncbi.nlm.nih.gov/31881541/ 